\title{
BIOECONOMIA E SUAS APLICAÇÕES
}

\author{
Rafael Gouveia Mejias ${ }^{1}$
}

\section{Resumo}

Este artigo busca entender como surgiu a Bioeconomia e apresentar diferentes definições para o termo, identificando suas áreas de competência. A bibliografia consultada observa que a biotecnologia e a bioeconomia são, por muitas vezes, relacionadas. Ao longo do artigo são apresentados projetos que mostram como a bioeconomia pode ser posta em prática. Porém, foi observado que alguns desses projetos são utilizados como estratégia de marketing, não estando comprometidos com o real intuito da bioeconomia. Na conclusão foram apontadas algumas controvérsias com relação à bioeconomia, e apresentados projetos que realmente contribuem para um desenvolvimento sustentável.

Palavras-chave: sustentabilidade, economia, biotecnologia, bioeconomia.

\begin{abstract}
This article intends to understand how Bioeconomy emerged and also to present, by identifying its areas of competence, the different definitions for the term. The consulted references have observed that biotechnology and bioeconomy are often related. Throughout the article are presented projects that show how the bioeconomy can be put into practice. However, it was observed that some of these projects are used as a marketing strategy only, not being committed to the real purpose of the bioeconomy. At the conclusion were pointed out some controversies regarding the bioeconomy, and presented projects that really contribute to a sustainable development.
\end{abstract}

Keywords: sustainability, economy, biotechnology, bioeconomy.

\footnotetext{
${ }^{1}$ Universidade Federal do ABC. E-mail: rafa.mejiass@hotmail.com 


\section{Introdução}

A partir do século $\mathrm{XX}$ as mudanças climáticas passaram a ser mais discutidas e notadas pelos pesquisadores, que começam a debater como viabilizar um desenvolvimento sustentável. As propostas para um desenvolvimento sustentável impactam diretamente na economia e nas mudanças de tecnologias utilizadas pelos países. Nesse sentido, foram desenvolvidas tecnologias alternativas para conseguir aumentar a produção e, ao mesmo tempo, mantendo a capacidade de produção sustentável, ou seja, conservando o meio ambiente e os recursos naturais para que as próximas gerações também possam deles usufruir. Nesse contexto, a bioeconomia surge como uma ciência transdisciplinar ${ }^{2}$ para auxiliar em tais questões.

Ainda que a bioeconomia seja uma ciência relativamente nova e não totalmente delineada, este trabalho tem como objetivo analisar a bioeconomia, sua origem e seu desenvolvimento. Através de algumas definições de bioeconomia, propostas por diferentes autores, e da análise de projetos com foco na bioeconomia, este artigo busca entender quais os avanços esta ciência já proporcionou - e quais podem ser as suas perspectivas futuras. De posse de tais informações, será apresentada uma breve reflexão sobre alguns pontos ainda controversos em relação ao tema.

\section{Definições e surgimento da Bioeconomia}

As mudanças climáticas começaram a ser mais discutidas a partir do século $\mathrm{XX}$, quando a Organização das Nações Unidas (ONU) desenvolveu diversos estudos relacionados ao tema, e propôs o termo "desenvolvimento sustentável". O assunto apresentou tamanha relevância, que foi elaborado um relatório pela Comissão Mundial para o Meio Ambiente e o Desenvolvimento (CMMAD) contendo questões sociais, principalmente relacionadas aos fatores ambientais; tais informações foram colhidas pela comissão ao longo de três anos de pesquisa. No relatório, a comissão define: "o desenvolvimento sustentável é aquele que atende as necessidades do presente sem comprometer as possibilidades de as gerações futuras atenderem suas próprias necessidades" (ONU, 1963). Desde então ocorreram outras conferências, em que o principal foco seria estabelecer acordos entre os países para realizar mudanças visando o desenvolvimento sustentável (BARBOSA, 2008, p. 4).

\footnotetext{
${ }^{2}$ Uma ciência transdisciplinar é capaz de produzir uma interação entre disciplinas, relacionando várias disciplinas e promovendo sua interação, diferente de uma ciência interdisciplinar que apenas atinge duas disciplinas diferentes. (DICIO, 2018)
} 
Propostas para um desenvolvimento sustentável impactam diretamente na economia e nas mudanças de tecnologias utilizadas pelos países. Nesse sentido, foram desenvolvidas tecnologias alternativas para conseguir aumentar a produção mantendo a capacidade de produção sustentável, ou seja, conservando o meio ambiente e os recursos naturais - para que as próximas gerações também possam deles usufruir. Para isso, deve-se considerar não só os recursos naturais, mas também o espaço socioambiental. Seria necessária uma maneira de continuar produzindo de modo que fosse possível conservar a diversidade biológica, gerar resíduos apenas na quantidade que o ecossistema pudesse assimilar ou reciclar, utilizar recursos naturais esgotáveis de uma forma que não exceda a capacidade de substituição do ambiente, e também diminuir a desigualdade social (MONTIBELLER, SOUZA, 2012, p. 23). Estas propostas têm como objetivos mudanças graduais, que são motivadas por fatores econômicos e políticos, buscando formas alternativas de energia e produtos obtidos a partir de organismos vivos (GRANDO, 2013). Tendo em vista as políticas dos países com foco nos assuntos mencionados, e até mesmo a realização de acordos globais tendo como tema central os impactos ambientais, os países começaram a buscar novas tecnologias para encontrar alternativas ao desenvolvimento econômico já estabelecido. A bioeconomia surge como uma ciência transdisciplinar para auxiliar em tais questões.

A Bioeconomia é uma ciência que busca o desenvolvimento econômico de forma sustentável, ou a forma mais sustentável/compatível possível com o crescimento econômico. Nicholas Georgescu-Roegen foi um dos primeiros a notar a relação entre a economia e a biologia; ele chamou a atenção para a insustentabilidade do crescimento, pois notou que os recursos naturais disponíveis para a exploração na Terra não seriam compatíveis com o padrão que estava se estabelecendo (GEORGESCU-ROEGEN, 1971, p. 57). Desde então, diversos pesquisadores sugerem qual seria a área de atuação da (e o que seria a) Bioeconomia. Em um relatório da Harvard Business Review Brasil há uma menção acerca da bioeconomia:

A bioeconomia surge como resultado de uma revolução de inovações aplicadas no campo das ciências biológicas. Está diretamente ligada à invenção, ao desenvolvimento e ao uso de produtos e processos biológicos nas áreas da saúde humana, da produtividade agrícola e da pecuária, bem como da biotecnologia. (HBR Brasil, 2013, p. 15)

Outra proposta para a definição da bioeconomia foi sugerida pela Organização para a Cooperação e Desenvolvimento Econômico (OECD), que entende a bioeconomia como:

(...) um mundo onde a biotecnologia contribui com parcela importante da produção econômica. Sua emergência está relacionada a princípios relativos ao desenvolvimento sustentável e sustentabilidade ambiental, envolvendo 
quatro elementos: biotecnologia, conhecimento, biomassa renovável e integração entre aplicações. (OECD, 2009)

Cada vez mais biotecnologia e bioeconomia estão sendo relacionadas por diversos autores. $\mathrm{O}$ uso do termo bioeconomia tem sido entendido por um vínculo mais estreito com os conhecimentos associados à biotecnologia, e com as suas diversas técnicas (JUMA, KONDE, 2001, p. 15). Segundo Assad, a biotecnologia:

refere-se a um conjunto amplo de tecnologias habilitadoras e potencializadoras envolvendo a utilização, alteração controlada e a otimização de organismos vivos ou suas partes funcionantes, células e moléculas para a geração de produtos, processos e serviços. Seus resultados são aplicáveis e utilizados por diversos setores, como saúde, agroindústria e meio ambiente, e envolvem várias áreas do conhecimento, [...] utilizando técnicas inovadoras e promovendo revoluções no tratamento de doenças, no uso de novos medicamentos para aplicação humana e animal, na multiplicação e reprodução de espécies vegetais e animais, no desenvolvimento e melhoria de alimentos, na utilização sustentável da biodiversidade, na recuperação e tratamento de resíduos, dentre outras áreas com potencial crescente de aplicação. (ASSAD, 2002)

Para Aragão (2003), a "biotecnologia é o uso de seres vivos e seus componentes na agricultura, alimentação e saúde, além do emprego na produção ou modificação de produtos em processos industriais". Desta forma, pode-se perceber a tendência em unir a bioeconomia à biotecnologia, e em como elas convergem em diversos aspectos. A propósito, a biotecnologia pode ser utilizada como uma das principais ferramentas para avanços na Bioeconomia (ARAGÃO, 2003).

As pesquisas em biotecnologia têm avançado no mundo todo, porém, conforme avançam, encontram diversos problemas, em parte devido à falta de conhecimento e dos fatores limitadores - por exemplo, de até onde a biotecnologia poderia avançar. Os avanços da biotecnologia na década de 1990 influenciaram na realização da Convenção sobre Diversidade Biológica (CDB). Essa convenção originou um acordo internacional de direito ambiental, que foi assinado durante a Conferência das Nações Unidas sobre Meio Ambiente e Desenvolvimento, realizada na cidade do Rio de Janeiro em junho de 1992. O Conselho Administrativo da United Nations Environmental Proteccion (UNEP) estabeleceu um Grupo de Trabalho de especialistas em diversidade biológica, para promover a criação de uma convenção global sobre o tema. Esta convenção traz como objetivos: a conservação da diversidade biológica; a utilização sustentável de seus componentes e a repartição justa e equitativa dos benefícios derivados da utilização dos recursos genéticos, mediante, inclusive, o acesso adequado a estes recursos; e a transferência adequada de tecnologias pertinentes, instituídos pelo Decreto Legislativo $\mathrm{n}^{\circ} 2$ de 2004). A CDB também tratou sobre a 
biossegurança, pois, com o avanço das pesquisas nesta área, mostrou-se necessário estabelecer políticas de biossegurança ${ }^{3}$, para garantir a segurança alimentar e ambiental dos produtos geneticamente modificados. Os trabalhos originados dessa convenção incentivaram a elaboração do primeiro tratado internacional, o Protocolo de Cartagena sobre Biossegurança, para tratar especificamente das questões de segurança ambiental e alimentar dos transgênicos (MINISTÉRIO DO MEIO AMBIENTE, 2000).

No âmbito nacional, em 1994 o decreto legislativo $\mathrm{N}^{\circ} 2$ aprovou o texto da CDB, e em 2008 o Governo Federal lançou a Política de Desenvolvimento Produtivo - PND. Esta política coloca a biotecnologia como área estratégica para o desenvolvimento nacional. Do mesmo modo, o Decreto n. ${ }^{\circ} 6.041$ de 2007 instituiu a Política Nacional de Biotecnologia, visando criar condições e o ambiente adequado para a geração de inovações nesta área.

A bioeconomia ainda é uma ciência relativamente nova, e diversos pesquisadores sugerem definições e quais seriam as áreas correspondentes a esta ciência. Já a biotecnologia possui definições mais precisas, assim como suas áreas de atuação, sendo que, por vezes, se funde com os interesses da bioeconomia, de modo que alguns pesquisadores se refiram à biotecnologia como sendo um instrumento para aplicação da bioeconomia. Desta forma, percebe-se cada vez mais que as pesquisas relacionadas à biotecnologia e à bioeconomia estão avançando, fortalecendo ambas as áreas, que estão ganhando destaque em diversos países do mundo, e vão se tornando o foco de políticas públicas e pesquisas de diversos países.

\section{Bioeconomia no Brasil}

No Brasil (e no mundo) cada vez mais são incentivadas políticas para o desenvolvimento de pesquisas na área de bioeconomia. No Brasil, há a política da Mobilização Empresarial pela Inovação (MEI), e, com relação a esta política, a Confederação Nacional da Indústria (CNI) lançou, em 2011, uma agenda para estimular a inovação no país, abordando principalmente os temas associados à biotecnologia e à biodiversidade. Em outubro de 2012 a CNI realizou, em parceria com a HBR Brasil, o "Fórum de Bioeconomia: Desenvolvendo uma Agenda para o Brasil". O evento foi o primeiro debate internacional envolvendo várias áreas distintas sobre o assunto no país, mostrando a ambição da indústria brasileira para avançar nos aspectos econômico, social e ambiental do desenvolvimento da

\footnotetext{
${ }^{3}$ Biossegurança é o conjunto de medidas voltadas para a prevenção, a minimização ou a eliminação de riscos inerentes às atividades de pesquisa, produção, ensino, desenvolvimento tecnológico e prestação de serviços, que podem comprometer a saúde do homem, dos animais, do meio ambiente ou a qualidade dos trabalhos desenvolvidos. (TEIXEIRA, VALE, 1998, p. 13)
} 
bioeconomia no Brasil. Devido ao grande interesse dos pesquisadores, em 2013, a CNI e a HBR-Brasil promoveram o $2^{\circ}$ Fórum, onde o desafio foi propor uma agenda de bioeconomia para o Brasil (CNI, 2013).

No ano seguinte, em outubro de 2014, foi realizado o $3^{\circ}$ fórum de bioeconomia, que, por sua vez, teve como objetivo geral mapear o cenário da bioeconomia no Brasil, e identificar obstáculos e oportunidades para a consolidação do tema no país. O mapeamento foi realizado por meio de entrevistas, e contou com a participação de 160 pessoas, tanto os especialistas no assunto quanto aqueles que não detinham conhecimento específico sobre o tema. Nesta pesquisa, foi analisado o estágio de maturidade do país em relação ao entendimento e ao conhecimento sobre o que é, de fato, a bioeconomia, e avaliado o potencial de crescimento que o país possui nesta área. A pesquisa relatou que cerca de $50 \%$ dos participantes detém pouco ou nenhum conhecimento sobre a bioeconomia, e de como ela afeta e afetará, não só a economia, mas também o comportamento da sociedade quanto ao uso de recursos naturais, e ao consumo de seus derivados. Situação que sugere uma fragilidade do país, tendo em vista que grande parte dos entrevistados representam instituições diretamente inseridas em setores da cadeia de valor da bioeconomia, e onde a biotecnologia desempenha um papel crucial no negócio. Porém, aproximadamente 50\% dos representantes de empresas afirmaram que aumentaram seus investimentos em bioeconomia nos últimos três anos, e o mesmo percentual afirmou acreditar que este investimento continuará crescendo nos próximos 3 anos, e o mesmo percentual afirma acreditar que este investimento continuará crescendo nos próximos três anos. Mais de $70 \%$ dos entrevistados acreditava que o Brasil não estaria aproveitando seu potencial para o desenvolvimento da bioeconomia, e que as atuais linhas de apoio à pesquisa no Brasil não são suficientes para o mesmo. Com relação à competitividade do Brasil, $68 \%$ dos respondentes classificaram o país como pouco competitivo e com baixa maturidade nas áreas relacionadas, devido a diversos motivos, como, por exemplo, a baixa qualificação, a escassez de mão de obra, e a falta de segurança jurídica para o investimento em pesquisa e desenvolvimento (CNI, 2014).

Um dos programas existentes no Brasil que tem contribuído para o avanço das pesquisas na área de bioeconomia é o Programa de Subvenção Econômica à Inovação Nacional. Este programa tem como objetivo "apoiar por meio da concessão de recursos de subvenção econômica o desenvolvimento por empresas brasileiras de produtos, processos e serviços inovadores", tendo sido fundamentado na Lei $N^{\circ} 10.973 / 2004$. No Amazonas, o programa de subvenção foi lançado com a denominação de Programa Amazonas de Apoio à 
Pesquisa, Desenvolvimento Tecnológico e Inovação em Micro e Pequenas Empresas, na Modalidade Subvenção Econômica - Pappe Subvenção Finep Amazonas, liderado pela Fundação de Amparo à Pesquisa do Estado do Amazonas (Fapeam) (FINEP). No caso particular do estado do Amazonas, o objetivo estabelecido para o Programa é incentivar o desenvolvimento de projetos de inovação tecnológica, visando ao aumento da cultura de inovação e a competitividade das MPEs sediadas no Estado (ARAÚJO, 2011).

Nota-se como a bioeconomia e a biotecnologia têm avançado no Brasil, através da análise dos dados preliminares da pesquisa da Food and Administration Organization of the United Nations (FAO/UN), realizada em 2012. A pesquisa apontou que $82 \%$ da soja, $68 \%$ do algodão, $30 \%$ do milho e $25 \%$ da canola produzidas no planeta já envolviam biotecnologia no seu processo de produção. Com relação à geração de energia a partir de recursos renováveis existentes na natureza, os novos conhecimentos sobre a biossíntese $\mathrm{em}^{4}$ leveduras e suas aplicações no campo dos biocombustíveis ${ }^{5}$, as produções foram muito maiores do que se esperaria anos atrás. A produção de biocombustível (etanol e biodiesel) cresceu $5.200 \%$ entre 2001 e 2002 , o que demonstra como essa fonte de energia tornou-se relevante na sociedade. Dados de 2014 e 2015 mostram que esse mercado continua em evolução, alcançando 144,02 e 148,02 bilhões de litros, respectivamente (OECD, 2015).

Outro segmento que, podendo ser relacionado com a bioeconomia e o Brasil, tem mostrado resultados significativos é o controle biológico de plantações, com utilização direta de organismos vivos ou de substâncias obtidas a partir dos mesmos e bioinseticidas ${ }^{6}$. O controle biológico de pragas, também chamado de manejo integrado de pragas (MIP), tem sido utilizado em plantações para controlar os insetos-praga nas culturas. Nesse processo, há a utilização de agentes naturais e do uso racional de defensivos agrícolas para o controle de pragas, sendo que tem como principais vantagens não deixar resíduo no ambiente - e não ser tóxico para os humanos (SIMONATO, 2014).

Assim, o Brasil mostra que possui vantagens comparativas e competitivas para avançar nas pesquisas relacionadas à bioeconomia, principalmente com relação à produção de biocombustíveis. O país possui culturas agrícolas de grande extensão, intensa radiação solar, água em abundância, ampla biodiversidade e diversidade de clima. Estes fatores auxiliam no desenvolvimento do Brasil nestas áreas, e também atrai a atenção de investidores estrangeiros

\footnotetext{
${ }^{4}$ Biossíntese é a formação de uma substância orgânica em um ser vivo. (DICIO, 2018)

5 Biocombustível é o combustível fabricado a partir dos extratos retirados dos vegetais, óleos ou matéria orgânica. (DICIO, 2018)

${ }^{6}$ Bioinseticida é o produto desenvolvido a partir de organismos vivos e que não possuem substâncias químicas, não sendo ofensivo ao meio ambiente. (DICIO, 2018)
} 
para a implementação de projetos inovadores, baseados em novas tecnologias, e visando o desenvolvimento de novos produtos (GRANDO, 2013).

\section{Aplicações e perspectivas da Bioeconomia}

Como citado anteriormente, o Brasil tem apresentado um grande potencial no controle biológico de plantações. Um exemplo de sucesso é o controle da principal praga da cana de açúcar, a broca da cana (Diatraea saccharalis). O controle dessa praga na cultura da cana de açúcar é realizado basicamente com agentes de controle biológico, um parasitoide larval e um parasitoide de ovos. O parasita Trissolcus basalis é utilizado para o controle de percevejos fitófagos ${ }^{7}$, e o Baculovirus anticarsia para o controle da lagarta da soja (Anticarsia gemmatalis) (SIMONATO, 2014, p. 70). O controle da lagarta da soja, realizado com o uso de Baculovirus anticarsia, foi desenvolvido e estimulado pela Embrapa. Na safra 1997/1998, esse vírus foi utilizado em 2 milhões de hectares de soja no Brasil, tornando-se o maior programa de controle biológico na ocasião (MOSCARDI ET AL., 2011). Desde então, esse vírus foi utilizado em mais de 10 milhões de hectares, proporcionando ao país uma economia estimada em US\$ 100 milhões em agrotóxicos, além dos benefícios ambientais proporcionados pela não aplicação de mais de 11 milhões de litros desses produtos (DIAS, 2017, p. 410).

Na geração de energia, o Brasil também aplica a biotecnologia, com a utilização dos biocombustíveis. O Brasil apresenta um crescimento continuado na obtenção de energia a partir da biomassa de cana-de-açúcar. Em 2010 foram gerados 10.141 GWh de energia a partir da biomassa de diversas origens. Em 2015 esse número aumenta para $22.572 \mathrm{GWh}$ (116,75\% de aumento), sendo que $89 \%$ desse total foram obtidos a partir da biomassa de cana de açúcar. Para analisar como esses números impactam de fato na economia do país, pode-se fazer algumas comparações. Esse volume de energia é suficiente para abastecer mais de 10 milhões de residências, além de proporcionar a redução de 8,6 milhões de toneladas em emissões de $\mathrm{CO}_{2}$ na atmosfera, e evitar o uso de $14 \%$ da água nos reservatórios das hidrelétricas. Com a busca mundial por tecnologias mais sustentáveis, esses produtos têm sido mais procurados, o que confere uma vantagem ao Brasil. $\mathrm{O}$ agronegócio relacionado aos biocombustíveis é um forte gerador de empregos e de renda no Brasil, desta forma, aumentar a sua produção ajudaria a desenvolver regiões (hoje com baixo índice de desenvolvimento), além de reduzir sua dependência do petróleo. Não seria possível aumentar apenas a renda da

\footnotetext{
${ }^{7}$ Fitófagos são animais que se nutrem de matérias vegetais. (FITÓFAGOS, 2018) 
região, mas também a do país, pois poderia realizar a exportação do excedente da produção dos biocombustíveis e a negociação dos créditos de carbono (OLIVEIRA, 2015, p. 23).

$\mathrm{O}$ Brasil tem sido um dos principais atores com relação à agricultura, pois tem mostrado um grande avanço na condução de pesquisas transgênicas ${ }^{8}$, isto devido ao suporte de instituições como a Embrapa e as Universidades Públicas. A soja se apresenta como produto principal para o Brasil neste quesito. Em 2005, no Brasil foi liberada a soja transgênica, e no mesmo ano foi criada a Comissão Técnica Nacional de Biossegurança (CTNBio), através da Lei $\mathrm{N}^{\circ} 11.105 / 2005$, para fornecer apoio técnico consultivo ao governo federal no que diz respeito à Política Nacional de Segurança relacionada a organismos geneticamente modificados (OGMs). Em 2009, o Brasil tornou-se o segundo maior produtor a utilizar plantas geneticamente modificadas, atrás apenas dos Estados Unidos (CARRER, 2011). As técnicas de biotecnologia também podem ser utilizadas para melhorar a eficiência de micro-organismos que participam de atividades de biorremediação ${ }^{9}$. Alguns microorganismos já são utilizados para tratamento de águas e solos com resíduos, e para a recuperação de metais (como o de rejeitos rochosos nas atividades de mineração), pois as bactérias e fungos utilizados se alimentam de substâncias que estão nas rochas com minério (OECD, 2006).

A Amyris Biotechnologies, fundada em 2003 nos Estados Unidos, é uma empresa que tem avançado em pesquisas na área de biotecnologia (AMYRIS, 2010). Em 2005 a companhia recebeu uma doação de mais de US\$ 40 milhões da fundação Bill e Melinda Gates, para colaborar com pesquisas para a produção sintética de um princípio ativo de um medicamento utilizado para tratar pessoas infectadas pela malária, a artemisina. Este composto era originalmente extraído de uma planta (Artemisia annua), exigindo grande quantidade do vegetal e procedimentos de purificação delicados, o que tornava sua produção cara. Então, a companhia focou suas pesquisas em outras formas de produção de tal composto. Através do uso da engenharia genética e da biologia molecular, conseguiu utilizar a bactéria Escherichia coli como veículo de produção, sintetizando quimicamente o composto, diminuindo o custo de produção e tornando mais viável economicamente, além de minimizar o impacto ambiental. Em 2008 a companhia criou uma subsidiária no Brasil, a Amyris Brasil S.A, com a função de desenvolver processos em escala industrial para a produção e a

\footnotetext{
${ }^{8}$ Transgênico é qualquer organismo que, por transformação, teve sua constituição genética alterada pela introdução de gene(s) de um outro organismo. (KREUZER; MASSEY; 2001, p. 50)

${ }^{9}$ Biorremediação é a utilização de organismos vivos para recuperar áreas poluídas. (DICIO, 2018) 
comercialização de bioprodutos, especialmente os relacionados com o diesel, devido ao grande potencial que identificou no Brasil (GRANDO, 2013).

$\mathrm{Na}$ área da biotecnologia industrial para a produção de biocombustíveis, a empresa Solazyme tem demonstrado grandes avanços. A Solazyme foi fundada em 2003 e possui sua sede na Califórnia, EUA. A empresa é pioneira no desenvolvimento de uma biotecnologia industrial para transformar açúcares em óleos renováveis, com a utilização de microalgas como catalisador. A Solazyme iniciou suas pesquisas com o objetivo de utilizar algas para produção de combustíveis, utilizando equipamentos específicos para que a alga pudesse realizar fotossíntese. Com o avanço das pesquisas, notaram que, com os processos utilizados até o momento, não seriam capazes de produzirem grandes volumes com as algas, portanto, adotaram novas estratégias - utilizando manipulação genética, com o auxílio da biologia molecular. Desta forma, conseguiram manipular as algas, de forma que passaram a produzir mais óleo e a realizar metabolismo heterotrófico ${ }^{10}$. Com o avanço das pesquisas, a empresa foi recebendo mais investimentos, e, em 2008, lançou o Soladiesel, um biodiesel 100\% renovável, que possui as mesmas características químicas do diesel convencional. (SOLAZYME, 2011).

Outro fator que gera bastante debate (em relação ao desenvolvimento sustentável) é a geração de resíduos e os seus descartes, sendo o setor madeireiro e o agrícola grandes geradores de resíduos. Os resíduos gerados nessas atividades apresentam dificuldade de transporte, acumulando matéria-prima sem valor que pode ocasionar problemas ambientais, como gases que contribuem para o aquecimento global. Um estudo de 2011 procurou apresentar a fibra de coco verde como alternativa na construção civil, minimizando os impactos dos resíduos de construções. Atualmente, o que é mais utilizado no mercado da construção civil são os painéis de cimento-madeira, e o estudo verificou que a fibra do coco verde poderia ser utilizada como alternativa, desde que tratada com algumas substâncias (água quente, $\mathrm{NaOH}$ e $\mathrm{CaCl}_{2}$ ) que reduzem o efeito inibitório das fibras, para melhor adesão ao cimento (FERRAZ, 2011).

O coco verde também tem sido alvo de outras pesquisas, como o seu uso para substrato agrícola. O consumo de água de coco tem aumentado no Brasil, e o coco verde é um material de difícil decomposição, levando em torno de oito anos para se decompor. Dessa forma, a casca do coco verde pode ser processada e utilizada como matéria-prima para

\footnotetext{
${ }^{10}$ Organismos heterotróficos são aqueles que se alimentam de outros organismos ou de resíduos orgânicos produzidos por outros organismos. (HETEROTRÓFICOS, 2018)
} 
produção de substratos de boa qualidade, e, então, ser utilizada na produção de mudas ou em cultivos sem o uso do solo. Desta forma, há a transformação de algo que era considerado lixo, em algo com valor, mostrando a importância econômica, social e ambiental que poderia ser agregada (CARRIJO, 2002, p. 533).

Pode-se notar que há diversas pesquisas realizadas nesta área, devido à grande importância dessa nova ciência, e que, nos últimos anos, as pesquisas relativas à bioeconomia aumentaram, principalmente quanto as que utilizam a biotecnologia. Mas, em um estudo realizado até 2006, a OECD (2009) mostra o número de pedidos de patentes biotecnológicas enviadas via Acordo Internacional de Patentes (Patent Cooperation Treaty - PCT), onde se pode notar que estas pesquisas não estão igualmente desenvolvidas no mundo. A maioria é originada nos Estados Unidos (41,5\%), e o restante está distribuído entre União Europeia $(27,4 \%)$, Japão $(11,9 \%)$, BRICS $^{11}(4,0 \%)$ e outros países $(15,1 \%)$, indicando que há um grande potencial a ser trabalhado pela maioria dos países (OECD, 2009).

\section{Controvérsias na Bioeconomia}

Há algumas políticas que têm como foco prever e minimizar esses impactos, desde que isso não atrapalhe significativamente o crescimento econômico do país. $\mathrm{O}$ "Princípio da Precaução" foi definido na Conferência das Nações Unidas para o Meio Ambiente e Desenvolvimento, reunida no Rio de Janeiro em 1992, em que se aprovou a "Declaração do Rio de Janeiro", e tem sido amplamente discutido desde então. O Princípio 15 desta Declaração estabelece que o "Princípio da Precaução" deve ser amplamente observado pelos Estados, visando à proteção do meio ambiente. Segundo o mesmo princípio, deve-se agir quando houver ameaças de danos sérios e irreversíveis, ainda que haja incerteza sobre as evidências. A ausência de absoluta certeza científica não deve ser utilizada como razão para postergar medidas eficazes e economicamente viáveis para prevenir a degradação ambiental (MINISTÉRIO DO MEIO AMBIENTE, 2004).

Quando uma planta é geneticamente modificada, há a introdução de um novo DNA, que possui efeitos intencionais (por exemplo, conferir resistência a determinado herbicida), e efeitos não intencionais, que podem ser previsíveis ou não (mudanças morfológicas na planta, alteração da composição química, aumento da toxicidade da planta). Com relação a esses efeitos não intencionais, deve-se tomar mais cuidado, pois podem comprometer a saúde

\footnotetext{
${ }^{11}$ BRICS é o nome de um conjunto econômico de países considerados emergentes, formado pelo Brasil, Rússia, Índia, China e África do Sul. (REIS, Maria Edileuza Fontenele, 2012, p. 344)
} 
humana e a segurança ambiental. Introduzir plantas geneticamente modificadas em um ecossistema apresenta riscos potenciais do ponto de vista ecológico. Essa planta introduzida pode originar novas plantas daninhas, amplificar os efeitos de plantas daninhas já existentes, causar danos à espécies não-alvo, alterar o fluxo gênico, desequilibrar o ecossistema e levar à perda de diversidade biológica. Esses fatos requerem atenção especial, principalmente de países como o Brasil, que possuem uma ampla biodiversidade (AMÂNCIO, 2010).

Apesar dos grandes avanços em relação à bioeconomia, principalmente quando relacionada com a biotecnologia e com as diversas políticas de biossegurança, ainda há pontos nessas pesquisas que não estão bem definidos. Tendo em vista que a bioeconomia visa a um desenvolvimento sustentável, buscando diminuir o impacto no ambiente, quando há a utilização de organismos geneticamente modificados muitos estudos não provam, a longo prazo, que aqueles organismos não causarão nenhum impacto no ambiente ou na saúde humana. As pesquisas realizadas com os organismos geneticamente modificados fazem uma previsão a curto e a médio prazos, sendo que, a longo prazo, há poucas pesquisas conclusivas. Desta forma, a utilização destes organismos, se não for muito bem regulamentada e vigiada, pode causar grandes impactos irreversíveis aos ecossistemas, à saúde animal e à saúde humana.

Como um desenvolvimento sustentável almeja também benefícios no âmbito social, as políticas focadas em bioeconomia devem promover a descentralização dos recursos humanos e financeiros. Quando os investimentos são realizados sempre nos mesmos locais, acabam favorecendo o desenvolvimento daquela região (em comparação com as outras), colaborando para a desigualdade social. Ou, então, há a exploração dos recursos naturais de uma região para a obtenção de matéria-prima que será enviada para outra região, e gerar riquezas lá, empobrecendo e degradando a região de origem da matéria-prima.

Conciliar desenvolvimento sustentável e expansão econômica é uma proposta bastante desafiadora. O sistema econômico vigente no mundo caracteriza-se, principalmente, pela acumulação de capital, tentando conciliar-se com discursos de conservação ambiental. Mas esse modelo econômico, ao mesmo tempo que propaga um discurso universal de defesa ao meio ambiente, estimula políticas de desregulamentação e o uso insustentável da natureza. Cavalcanti (2004) mostra como este discurso se torna incoerente com a Amazônia. Enquanto se afirma uma preocupação com a Amazônia, são cortadas as verbas destinadas à fiscalização ambiental, sendo que a falta de fiscalização ambiental gera enormes impactos ambientais e sociais. 
Em grande parte das sociedades, industrializadas ou em processo de industrialização, considera-se que o crescimento do Produto Interno Bruto (PIB) é a melhor forma de minimizar os problemas econômicos e sociais (MARTÍNEZ-ALIER, 1998). Porém, quanto maior o PIB de uma economia, em geral, maiores são suas taxas de exploração dos recursos naturais e maior é o esgotamento dos recursos não-renováveis, bem como maior a geração de resíduos e, consequentemente, o desperdício. No período de cinquenta anos após a Segunda Guerra Mundial, a população do Brasil praticamente triplicou e o PIB aumentou mais de 12 vezes. Mas tais avanços se deram paralelamente à extração de recursos minerais, aos desmatamentos maciços, às queimadas para formação de pastagens e, consequentemente, à perda da biodiversidade, entre outras práticas nocivas ao ambiente. $\mathrm{O}$ aumento expressivo do PIB não trouxe benefícios significativos para minimizar a desigualdade de renda; pelo contrário, aumentou para $21,5 \%$ a população situada abaixo da linha de pobreza nos anos 1990. Portanto, constata-se que o crescimento, ao se relacionar somente ao aspecto econômico, não promove o desenvolvimento econômico de toda a população, e, ainda menos, um desenvolvimento sustentável (MONTIBELLER; SOUZA, 2012).

A ONU retomou o debate das questões ambientais no início da década de 1980, e, então, instituiu a Comissão Mundial sobre o Meio Ambiente e Desenvolvimento, para promover estudos relacionados ao assunto. Criada em 1983, a comissão teve como objetivo promover audiências em todo o mundo para debater o assunto, e divulgar o resultado formal das discussões. O resultado final foi o documento chamado Nosso Futuro Comum, ou Relatório Brundtland. O relatório Brundtland chamou a atenção do mundo sobre a necessidade de se encontrar novas formas de desenvolvimento econômico, sem a redução dos recursos naturais e sem danos ao meio ambiente. Além disso, definiu três princípios básicos a serem cumpridos: desenvolvimento econômico, proteção ambiental e equidade social. O relatório ressaltou que a pobreza pode ser considerada como um problema ambiental, sendo fundamental abordá-la para promoção de uma efetiva sustentabilidade (BARBOSA, 2008).

\section{Considerações finais}

A Bioeconomia tem se mostrado uma ciência com amplo potencial, e vem ganhando destaque nas políticas públicas de vários países. A biotecnologia pode ser entendida como a ferramenta para colocar a bioeconomia em prática. As técnicas utilizadas em biotecnologia têm, em sua maioria, como objetivo aumentar a produção e aprimorar os processos, auxiliando em um desenvolvimento sustentável. Este artigo registrou uma série de estudos 
propondo produtos e novas estratégias relacionados à bioeconomia, sendo o Brasil um dos países com maior potencial para desenvolver essa área. Porém, ainda seria necessário um incentivo extra do Estado para promover mudanças significativas.

Muitos países têm utilizado o desenvolvimento sustentável como um slogan político. A sustentabilidade tem como foco encontrar meios de produção, distribuição e consumo dos recursos existentes de forma mais eficaz economicamente e ecologicamente viável. Um desenvolvimento sustentável deveria gerar cidades produtoras com atividades que pudessem ser acessadas por todos, incorporando os elementos naturais e sociais. Porém, muitos países acabam tendo como foco principal o crescimento e não o desenvolvimento, ou até mesmo tratando erroneamente os dois com o mesmo significado. Dificilmente o crescimento proporcionará uma diminuição significativa na pobreza e na degradação ambiental. Diante disso, nota-se a necessidade de um desenvolvimento urbano sustentável, diferente do desenvolvimento atual, que é baseado no lucro e privilegia uma pequena parte da sociedade; onde aumentar o PIB não significa, necessariamente, o desenvolvimento do país.

Apesar de a bioeconomia demonstrar ser uma ciência fundamental para o desenvolvimento sustentável e para a preservação dos recursos ambientais no mundo, ao longo deste artigo percebe-se que muitas pesquisas desenvolvidas na área da bioeconomia estão relacionadas, antes, com o crescimento econômico, e não com o desenvolvimento sustentável - ao qual a bioeconomia deve ser sempre relacionada. Deve-se, portanto, distinguir quais governos e empresas estão realmente incentivando a bioeconomia, com foco na preservação do planeta, daqueles que estão apenas utilizando o assunto como uma forma de marketing. São necessárias pesquisas e políticas públicas que tenham como real interesse a preservação da natureza, o respeito à identidade cultural de todos os povos (com diretrizes igualitárias), a redução dos desperdícios provocados pelos padrões de consumo dos povos mais ricos, e a diminuição da pobreza. 


\section{Referências Bibliográficas}

AMÂNCIO, M. C.; CALDAS, R. A. Biotecnologia no contexto da Convenção de Diversidade Biológica: análise da implementação do Art. 10 deste Acordo. Desenvolvimento e Meio Ambiente, Editora UFPR, n. 22, p. 125-140, dez. 2010.

ARAGÃO, F. J. L. Organismos transgênicos: explicando e discutindo a tecnologia. Barueri-SP: Manole, 2003.

ARAUJO FILHO, G.. Iniciativas em bionegócios e o programa pappe-subvenção no estado do Amazonas. 2011. Disponível em: https://tinyurl.com/ycb4mhyw. Acesso em: 23 de Março 2018.

ASSAD, A. L. D. (Coord.). Programa de Biotecnologia e Recursos Genéticos - Definição de Metas. Brasília, Secretaria de Políticas e Programas de Ciência e Tecnologia do MCT, 2002. Disponível em: https://tinyurl.com/ychn2ssl. Acesso em: 23 de Março 2018.

BARBOSA, G. S. O desafio do desenvolvimento sustentável. Revista Visões, v. 1, n. 4, Jan/Jun 2008.

BIOCOMBUSTÍVEL. DICIO, Dicionário Online de Português. Porto: 7Graus, 2018. Disponível em: https://www.dicio.com.br/biocombustivel/. Acesso em: 29 de setembro de 2018.

BIORREMEDIAÇÃO. DICIO, Dicionário Online de Português. Porto: 7Graus, 2018. Disponível em: https://www.dicio.com.br/biorremediacao/. Acesso em: 29 de Setembro de 2018.

BIOSSÍNTESE. DICIO, Dicionário Online de Português. Porto: 7Graus, 2018. Disponível em: https://www.dicio.com.br/biossintese/. Acesso em: 29 de Setembro de 2018.

BRASIL. Decreto Legislativo $n^{\circ}$ 2, de 3 de Fevereiro de 2004. Aprova o texto da Convenção da Diversidade Biológica, assinada durante a Conferência das Nações Unidas sobre Meio Ambiente e Desenvolvimento, realizada na cidade do Rio de Janeiro, no período de 5 a 14 de junho de 1992. Brasília, DF, 3 de Fev. 2004. Disponível em: https://tinyurl.com/y8n52cxh. Acesso em: 20 de Março de 2018.

BRASIL. Decreto $n^{\circ}$ 6.041, de 8 de Fevereiro de 2007. Política de Desenvolvimento da Biotecnologia. Brasília, DF, 8 de Fev. 2007. Disponível em: https://tinyurl.com/y6whlgcr. Acesso em: 20 de Março de 2018.

BRASIL. Lei $N^{\circ} \mathbf{1 0 . 9 7 3}$ de 2 de Dezembro de 2004. Dispõe sobre incentivos à inovação e à pesquisa científica e tecnológica no ambiente produtivo e dá outras providências. Disponível em: https://tinyurl.com/p8ykrf5. Acesso em: 23 de Março de 2018.

BRASIL. Lei $\mathbf{N}^{\mathbf{0}}$ 11.105, de 24 de Março de 2005. Regulamenta os incisos II, IV e V do $\S 1^{\mathrm{o}}$ do art. 225 da Constituição Federal. Disponível em: https://tinyurl.com/qhwgceb. Acesso em: 20 de Março de 2018. 
BRASIL. Ministério do Meio Ambiente - MMA. Princípio da precaução. 2004. Disponível em: https://tinyurl.com/y8h9suqd. Acesso em: 20 de Março de 2018.

BRASIL. Ministério do Meio Ambiente - MMA. Protocolo de Cartagena, 2000. Disponível em: https://tinyurl.com/ycoj6suk. Acesso em: 20 de Março de 2018.

CARRER, H. et al. Biotecnologia na agricultura. Estudos avançados. v. 24, n. 70, out. 2011.

CARRIJO, O. A. et al. Fibra da casca do coco verde como substrato agrícola. Horticultura Brasileira, Brasília, v. 20, n. 4, p. 533-535. Dezembro. 2002.

CAVALCANTI, C. Uma tentativa de caracterização da economia ecológica. Ambiente \& Sociedade, v. 7, n. 1, p.149-156, jan./jun. 2004.

CONFEDERAÇÃO NACIONAL DA INDÚSTRIA (CNI) e HARVARD BUSINESS REVIEW-BRASIL (HBR-BR). Bioeconomia - Uma Agenda para o Brasil. 2013.

CONFEDERAÇÃO NACIONAL DA INDÚSTRIA (CNI) e HARVARD BUSINESS REVIEW-BRASIL (HBR-BR). $3^{\circ}$ Fórum de Bioeconomia - Pesquisa sobre bioeconomia no Brasil. Out.2014.

DIAS, R. F.; CARVALHO FILHO, C. A. A. Bioeconomia no Brasil e no mundo: panorama atual e perspectivas. Revista virtual de química, Rio de Janeiro, v. 9, n. 1, p. 410-430. jan./fev. 2017.

EMPRESA BRASILEIRA DE INOVAÇÃO E PESQUISA - FINEP. Pappe integração. Disponível em: < https://tinyurl.com/ycx5cp3a> . Acesso em: 23 de Março de 2018.

FERRAZ, J. M. Produção e propriedades de painéis de fibra de coco verde (Cocos nucifera L.) em mistura com cimento Portland. Dissertação de mestrado em ciências florestais. Departamento de engenharia florestal, Universidade de Brasília, Brasília, DF, 89 p. 2011. Disponível em: <https://tinyurl.com/y6twbc63>. Acesso em: 23 de Março de 2018.

FITÓFAGOS. DICIO, Dicionário Online de Português. Porto: 7Graus, 2018. Disponível em: https://www.dicio.com.br/fitofago/. Acesso em: 29 de Setembro de 2018.

GEORGESCU-ROEGEN, N. The Entropy Law and the Economic Process. Cambridge, MA: Harvard University Press, 1971.

GRANDO, R. L. Startups e Modelos de Negócio em Bioeconomia: As Trajetórias de Amyris e Solazyme. Dissertação (Mestrado em Tecnologia de Processos Químicos e Bioquímicos) - Universidade Federal do Rio de Janeiro, Escola de Química, Rio de Janeiro, 2013.

JUMA, C.; KONDE, V. The New Bioeconomy - Industrial and Environmental Biotechnology in Developing Countries. Genebra, United Nations Conference on Trade and Development (UNCTAD), 15-16. Nov. 2001. 
MARTÍNEZ-ALIER, J. Da economia ecológica ao ecologismo popular. Blumenau: Ed. da FURB, 1998.

MONTIBELlER, G.; SOUZA, G. C. Economia Ecológica e Sustentabilidade Socioambiental. Revista Brasileira de Ciências Ambientais, n. 23, 2012.

MOSCARDI, F. et al. Baculovirus pesticides: present state and future perspectives. In: AHMAD et al. (Ed.). Microbes and microbial technology agricultural and environmental applications. London: Springer. p. 415-445, 2011.

OLIVEIRA, K. C. A Bioeconomia e os Biocombustíveis no cenário Brasileiro. Revista iPecege, v. 1, n. 2, p. 23-43, 2015.

ORGANIZATION FOR ECONOMIC CO-OPERATION AND DEVELOPMET - OECD

Biotechnology Statistics. Paris. OCDE, 2006. Disponível em: https://tinyurl.com/yc977wez. Acesso em: 01 de Abril de 2018.

ORGANIZATION FOR ECONOMIC CO-OPERATION AND DEVELOPMET - OECD. OECD/Food and Agriculture Organization of the United Nations (2015), OECD-FAO Agricultural Outlook 2015, OECD Publishing, Paris, 2015.

ORGANIZATION FOR ECONOMIC CO-OPERATION AND DEVELOPMET - OECD. The Bioeconomy to 2030: Designing a Policy Agenda. 2009. Disponível em: https://tinyurl.com/y81687tk. Acesso em: 23 de Março de 2018.

REIS, M. E. F. BRICS: surgimento e evolução. In: Mesa redonda: o Brasil, os BRICS e a agenda internacional / Apresentação do Embaixador José Vicente de Sá Pimentel. Brasília: FUNAG, 2012.

SIMONATO, J. et al. Controle biológico de insetos-praga na soja. Embrapa Agropecuária Oeste, 2014. Disponível em: https://tinyurl.com/y7awvxqp. Acesso em: 23 de Março de 2018.

SOLAZYME. Production of soladiesel from cellulosic feedstocks. 2011. Disponível em: https://tinyurl.com/y9ofegxl. Acesso em: 06 de Abril de 2018.

TEIXEIRA, P.; VALLE, S. Biossegurança: uma abordagem multidisciplinar. Rio de Janeiro: Editora Fiocruz; 1998.

TRANSDISCIPLINAR. DICIO, Dicionário Online de Português. Porto: 7Graus, 2018. Disponível em: https://www.dicio.com.br/transdisciplinar/ . Acesso em: 29 de Setembro de 2018. 